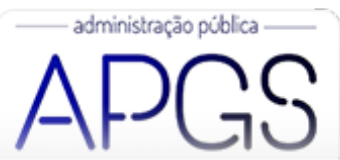

Administração Pública e Gestão Social ISSN: 2175-5787

apgs@ufv.br

Universidade Federal de Viçosa

Brasil

\title{
Ação Social Imanente: A Rede de Educação do Semiárido Brasileiro
}

\author{
Kraus, Lalita \\ Ação Social Imanente: A Rede de Educação do Semiárido Brasileiro \\ Administração Pública e Gestão Social, vol. 12, núm. 3, 2020 \\ Universidade Federal de Viçosa, Brasil \\ Disponible en: http://www.redalyc.org/articulo.oa?id=351563312010
}

Esta obra está bajo una Licencia Creative Commons Atribución-NoComercial-SinDerivar 3.0 Internacional. 


\title{
Ação Social Imanente: A Rede de Educação do Semiárido Brasileiro
}

\author{
Immanent Social Action: The Education Network of the Brazilian Semi-Arid \\ Acción Social Inmanente: La Red de Educación del Semiárido Brasileño
}

Lalita Kraus

Universidade Federal do Rio de Janeiro, Brasil

Redalyc: http://www.redalyc.org/articulo.oa?

kraus.lalita@gmail.com

$\mathrm{id}=351563312010$

Recepción: 21 Diciembre 2018

Aprobación: 26 Agosto 2019

Publicación: 01 Julio 2020

\section{Resumo:}

O objeto apresentado neste trabalho é a ação sociopolítica de uma rede sócio-governamental, a Rede de Educação do Semiárido Brasileiro (RESAB). Para tanto, será abordada a rede como uma forma de organizar a ação social no território semiárido brasileiro. A análise inclui a identificação dos elementos e das principais características que definem a essência da rede enquanto institucionalidade política imanente, com o objetivo de articular a ação em rede, o conceito de imanência e suas consequências em termos de democracia. Do ponto de vista metodológico, foram realizadas entrevistas, observações não participantes nos encontros da rede e a análise dos documentos produzidos pela RESAB. A pesquisa revelou que a ação da RESAB possibilita inúmeras inovações sociais, embora exista ainda um sistema de comunicação que impede uma plena ação imanente.

PalaVras-chaVe: Ação social, imanência, rede, democracia, Semiárido.

\section{Abstract:}

The object of the article is the socio-political action of a socio-governmental network, the Education Network of the Brazilian Semi-Arid (RESAB), which is presented as a way of organizing resistance in the Brazilian semi-arid territory. The analysis includes the identification of the elements and the main characteristics that define the essence of the network as an immanent political institution, in order to articulate the network action, the concept of immanence and its consequences in terms of democracy. The research methodology included interviews, non-participant observations in the network meetings and the analysis of the RESAB documents. The research revealed that the action of RESAB enables many social innovations, although there is still a system of communication that prevents a full immanent action.

KEYWORDS: Social action, immanency, network, democracy, semi-arid.

\section{RESUMEN:}

El artículo analisa la acción sociopolítica de una red socio-gubernamental, la Red de Educación del Semiárido Brasileño (RESAB). La red se presenta como una forma de organizar la resistencia en el territorio semiárido brasileño. El análisis identifica elementos y características principales que definen la esencia de la red como una institución política inmanente para articular la acción de la red y sus consecuencias en términos de democracia. La metodología de investigación utiliza entrevistas, observación participante en las reuniones de la red y el análisis de documentos oficiales. La investigación reveló que la acción de la RESAB permite innovaciones sociales, aunque todavía, existe un sistema de comunicación que impide una acción inmanente total.

Palabras clave: Acción social, inmanencia, red, democracia, Semiárido.

\section{INTRODUÇÃO}

O objeto de análise do presente artigo é a Rede de Educação do Semiárido Brasileiro (RESAB), uma articulação político-pedagógica cujo objetivo é consolidar uma proposta de educação contextualizada nas escolas do Semiárido, assim como contribuir para a formulação de políticas públicas educacionais, orientadas pelos princípios da convivência com o Semiárido (Resab, 2006). 
O ponto de partida da análise é, por um lado, a constatação da crise da democracia no mundo contemporâneo (Hardt \& Negri, 2000; Santos, 2002; Santos \& Avritzer, 2002). Jean-Marie Guéhenno (1999) ressalta que na atualidade a política apresentou falhas na gestão da res publica, tornando-se instrumento de representação de interesses privados. A autora define essa situação como engarrafamento político (Guéhenno, 1999). O nível de desigualdade e injustiça social ainda vigente, a falta de mecanismos e espaços de participação política efetiva por parte da população e de atendimento das demandas sociais são apenas alguns dos exemplos das contradições e vícios congênitos da concepção moderna de democracia representativa. Como resultado, nas últimas décadas a confiança do público nas instituições políticas erodiu, gerando um clima de fragilidade e recessão democrática (Dalton, 2004; Pharr \& Putnam, 2000).

Por outro lado, o presente estudo reconhece o valor ético e político das formas de resistência que os sujeitos e os movimentos desenvolvem para contrapor-se ao poder instituído e reverter as formas de injustiça social. Nesse sentido, pretendemos incluir o presente trabalho entre os estudos que apresentam o papel das articulações de movimentos sociais como um modo específico de alternativa política e de organização da ação social, segundo uma lógica de baixo para cima (Della Porta \& Diani, 2006; Passy, 2003; Scherer-Warren, 2011).

Em geral, o debate em torno da concepção e da natureza da democracia é complexo, insolúvel e multifacetado. O presente artigo se insere em um debate específico que aborda a questão a partir de alternativas políticas inconciliáveis: A perspectiva transcendente e a imanente. Assim, através da contribuição teórica de autores clássicos da filosofia e da teoria política, será aprofundado o conceito de transcendência (Hobbes, 1985; Rousseau, 1973), assim como de imanência (Deleuze \& Guattari, 2002; Negri, 2002; Hardt \& Negri, 2000; 2005; Machiavelli, 2013; Spinoza, 1994). O intuito é argumentar que a soberania e a representatividade representam elementos constitutivos do atual sistema democrático, caracterizando uma esfera transcendente de poder, que, agindo segundo uma lógica vertical, prescinde das vontades individuais (Hardt \& Negri, 2000; Santos, 2002). Isso impediria garantir e satisfazer os interesses e as demandas das populações, pois privilegiaria os interesses privados e de grupo restritos. Nesse sentido, investigar a ação da RESAB permite explorar o potencial democrático de uma ação oriunda dos movimentos sociais que, em contraposição ao plano transcendental, pode ter conotações de natureza imanente e possivelmente mais igualitárias e participativas.

Com o objetivo de investigar o potencial imanente da RESAB, após descrever a rede na primeira seção, na segunda será explorada a concepção de imanência e sua operacionalização. $O$ raciocínio analítico será desenvolvido aplicando o conceito de imanência à análise da rede, a partir das variáveis de interação, horizontalidade, autonomia e transversalidade. Tais variáveis foram identificadas a partir da teorização proposta por autores como Niccoló Macchiavelli, Baruch Spinoza e Antonio Negri. Após a definição dessas variáveis, as últimas seções apresentam os resultados do estudo. $\mathrm{O}$ modelo de análise incluiu a identificação de componentes específicos por cada variável que possam ser levantados e investigados através da pesquisa de campo. A interação é analisada a partir da dinâmica relacional entre os membros, enquanto o nível de horizontalidade é averiguado a partir da análise dos sistemas de representatividades internos da rede. A autonomia é indagada mediante a observação das possibilidades e limites da iniciativa de cada membro e, por último, a transversalidade é verificada a partir do nível de diversidade na composição da rede.

Para tanto, entre março de 2014 e setembro de 2016 foram realizadas 30 entrevistas e 5 focus group com membros da RESAB e da comunidade escolar (professores, diretores das escolas e assessores pedagógicos), 9 visitas em escolas municipais e participação observante em 8 encontros da RESAB.

\section{O SENTIDO DA REDE}

Durante um encontro da rede em 2014, ao responder às perguntas “O que a RESAB representa?" e “Qqual é o sentido de fazer parte dela?”, os participantes destacaram a importância política da ação em rede e da 
proposta de Educação Contextualizada para a Convivência com o Semiárido (ECCSA). Estes constituem os elementos caracterizantes da essência de sua ação social.

A RESAB reconhece, em primeiro lugar, sua identidade como rede sociogovernamental. $\mathrm{O}$ termo rede é amplamente utilizado em diferentes áreas e disciplinas, com significações distintas (Marteleto, 2001; 2010). Tornou-se uma espécie de palavra passe-partout que descreve processos físicos, biológicos, sociais, econômicos e políticos, evidenciando a riqueza e a diversidade de perspectivas que esse conceito proporciona e agencia. Como Scherer-Warren (1999) aponta, o conceito de rede é também abordado de forma diferentes nas várias disciplinas, como sociologia e geografia, e do ponto de vista metodológico na análise científica, nas técnicas de planejamento e na ação coletiva. No caso da RESAB, constituiu-se como rede porque "quando as instituições estão numa rede, isto fortalece muito a ação, e uma demanda e proposta local podem assim ter ressonância global". Isto revela a rede como estratégia de ação coletiva, ou seja, como uma forma de organização da ação social (Della Porta \& Diani, 2006; Egler, 2007; Martinho, 2003; Scherer-Warren, 1999).

A RESAB reúne atores governamentais como secretarias municipais de educação e secretarias estaduais de educação, mas também não governamentais, como organizações não governamentais (ONGs), pastorais, sindicatos, igrejas e universidades. A Figura 1 representa tal complexidade, destacando os membros da rede (nós) e suas respectivas relações (arestas), além de sua alocação geográfica (cor do nó). Durante a participação nos encontros da RESAB foi possível mapear seus membros, assim como a existência de relações que se constituem a partir de ações e projetos realizados em comum. A representação gráfica foi realizada através do software GEPHI.

$\mathrm{Na}$ RESAB encontramos, assim, indivíduos que representam instituições, assim como instituições e redes, como a Rede de Educação Contextualizada do Agreste e Semiárido (RECASA) em Alagoas; movimentos sociais como o Movimento Sem Terra no Ceará; organismos governamentais, como a Secretaria Estadual de Educação (SEDUC) no Piauí. A relação destacada nessa figura se refere à afiliação, isto é, o pertencimento à rede e o compartilhamento de um sentido comum.

Isto revela uma rede social complexa que transcende organizações formalmente identificáveis, conectando sujeitos individuais e atores coletivos de forma simbólica, solidária e estratégica, além das fronteiras institucionais, assumindo objetivos construídos coletivamente e compartilhados (Egler, 2007; Musso, 2013). Consequentemente, tratam-se de atores que atuam em âmbitos diferenciados, desde a formação com pequenos agricultores até a defesa dos direitos humanos, passando pelo apoio a comunidades tradicionais, entre outras. Essa complexidade é mantida coesa pelo reconhecimento e perseguição de um objetivo comum compartilhado, isto é, a ECCSA. Esse é o elemento que une e costura as diferenças.

Tal objetivo compartilhado, ou meta societal (Castells, 2000), é implementar e consolidar nas escolas da região semiárida uma proposta pedagógica de ECCSA, assim como contribuir para a formulação de políticas públicas educacionais (Martins, 2005; RESAB, 2006). Isto constitui o conteúdo social de sua ação. Assim, a ação da RESAB acontece nas escolas e em diferentes espaços políticos em nível federal, estadual e municipal. Trata-se de um projeto pedagógico, mas também político, na medida em que se trata de uma proposta de educação voltada para a convivência com o Semiárido e, portanto, para uma específica proposta de intervenção e desenvolvimento nesse território. 


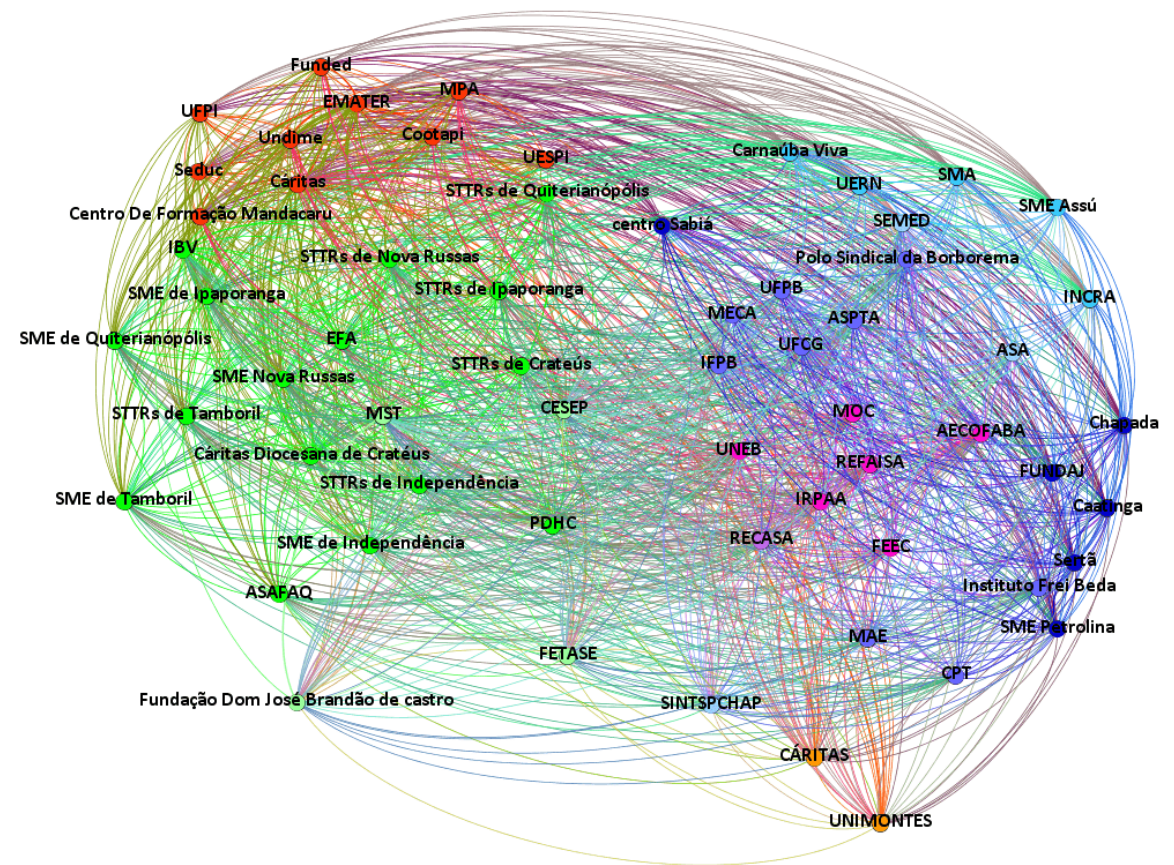

Figura 1. Representação dos membros da RESAB

Fonte: Elaboração do autor, a partir da pesquisa e campo e do software GEPHI[iv].

Trata-se de uma proposta pedagógica que almeja desencadear um processo de transformação cultural para que se possa afirmar um novo paradigma político de intervenção sustentável no território (Carvalho, 2007). Isto demonstra que, além de ser uma rede temática, que foca na ECCSA, existe um outro importante fator de propósito e aglutinação da RESAB, relativo à sua identidade territorial, pois a finalidade de sua ação é contribuir para um projeto político-pedagógico voltado para o Semiárido. Por isso, a rede atua em 11 Estados, a saber: Alagoas, Bahia, Ceará, Minas Gerais, Paraíba, Pernambuco, Piauí, Rio Grande do Norte, Sergipe, Maranhão e Espírito Santo.

O ponto de partida na elaboração da ação social da RESAB é o reconhecimento das especificidades ambientais da região semiárida e a crítica em relação às intervenções e à postura governamental no território. Para tanto propõe alternativas paradigmáticas em que a educação desempenhe um papel cultural e político importante, contribuindo para a construção de um novo modo de ver e viver no e como o Semiárido. Isto é, o foco territorial parte de dois pressupostos importantes: por um lado, o reconhecimento das formas de exploração econômica existentes no território e a ineficiência das intervenções governamentais. Por outro lado, a relevância de um processo de reinvenção pedagógica para propor um novo paradigma político e de intervenção no território, definido um sistema de inextrincabilidade entre a dimensão pedagógica, cultural e política.

Apesar da relevância do conteúdo social da ação da RESAB, o foco do presente artigo é apresentar e compreender seu caráter imanente na forma de se organizar, agir e desenvolver propostas políticas, como apresentaremos na próxima seção. 


\section{PERSPECTIVAS IMANENTES: AÇÃO SOCIOPOLÍTICA EM REDE}

A análise da ação social da RESAB focará na organização enquanto rede, assumindo como ponto de partida a constatação de que se distingue dos tradicionais aparatos político por sua arquitetura organizativa e seus princípios. $\mathrm{O}$ conceito de imanência possibilitará desenvolver tal análise.

Segundo Antonio Negri (2002), na modernidade existem duas alternativas inconciliáveis, que determinam modos de ver e de explicar o mundo, assim como pensar e gerar mudanças, a transcendência e a imanência. Trata-se de uma distinção que identifica a coexistência de práticas políticas e sociais autônomas, ou seja, imanentes, vindo dos sujeitos e contrárias à determinação intrínseca do real, e, ao mesmo tempo, mecanismos de controle, que tentam limitar tais dinâmicas liberatórias e transformadoras através de mecanismos transcendentes (Hardt \& Negri, 2000).

Autores clássicos como Thomas Hobbes (1985) e Jean-Jacques Rousseau (1973) reconhecem a transcendência soberana como única forma de governar e instituir a ordem mediante a mediação e a representação da vontade da maioria. $\mathrm{Na}$ contemporânea democracia representativa, as deliberações e decisões políticas, que dizem respeito à coletividade, são tomadas por representantes eleitos. Significa que indivíduos, ou cidadãos, elegem seus representantes e delegam a eles os poderes para tomar decisões, legislar e administrar em seu próprio nome. Opera, assim, uma civitas, um corpo político que transcende a individualidade dos cidadãos, na medida em que "eu [como cidadão] autorizo e entrego meu direito a me governar a este homem, ou a esta assembleia de homens, sob esta condição, de que tu entregues teus direitos a ele, e autorize todas as suas ações da mesma maneira" (Hobbes, 1985, p. 227).

Para os teóricos do contrato social (Hobbes, 1985; Rousseau, 1973), a realização do contrato permite passar do direito natural para o direito civil, eliminando os conflitos, que são sublimados no direito garantido pelo Estado. Assim, o direito e o Estado, pilares do contrato social, permitiriam superar a tensão entre imanência e transcendência, afirmando uma ordem superior aos indivíduos e à sociedade. Ao contrário, como veremos ao longo do artigo, para Spinoza (1994), não é possível substituir o direito natural pelo direito civil, pois existe uma potência e desejo de existência de cada um que não pode ser transferido e alienado no contrato social, deixando inconsistente qualquer ideia de representação. Essa operaria uma separação entre sujeito e o exercício da potência, na medida em que reduz a potência de muitos ao poder de poucos (Hardt \& Negri, 2000).

Além disso, o estado civil não necessariamente suprime as causas de sedição, de corrupção e de violação das leis. Isso é, a civitas não resolve a tensão entre imanência e transcendência, garantindo um estado de direito. Boaventura Santos e Leonardo Avritzer (2002) explicam essa impossibilidade ressaltando que a democracia representativa garante somente uma democracia "de baixa intensidade baseada na privatização do bem público por elites mais ou menos restritas, na distância crescente entre representantes e representados e em uma inclusão política abstrata" (Santos \& Avritzer, 2002, p. 32). Isto significa que, segundo os autores, o princípio de representatividade limita a participação cidadã e não garante a representação das diferenças, viabilizando e priorizando os interesses de poucos.

Desta forma, pode ser questionável a capacidade democrática de um corpus político transcendente (Negri, 2012) e sua capacidade de responder às demandas e exigências da população (Santos, 2002). Frente o vazio do projeto democrático contemporâneo, os sujeitos e os movimentos sociais com sua ação cotidiana abrem brechas na cultura política e carregam novos significados culturais e políticos em sua práxis, transformando as práticas sociais e os modos de participação política, delineando um novo sentido de democracia (Moulaert, Martinelli, Swyngedouw, \& Gonzalez, 2005; Negri, 2012). Mas de que forma e segundo quais princípios se constitui um corpus político imanente?

Alguns autores (Deleuze \& Guattari, 2002; Negri, 2002; Hardt \& Negri, 2000; 2005; Machiavelli, 2013; Spinoza, 1994) introduzem conceitos que contribuem para constituir uma reflexão política acerca da 
concepção da imanência, a partir da qual é possível liquidar qualquer concepção transcendental, restaurando um plano onde pode ser exercida a potência criativa e constituinte das subjetividades.

Negri (1981) faz uma leitura do pensamento de Spinoza numa perspectiva imanente, a partir da concepção de conatus enquanto direito natural, ou seja, a potência de cada um que se realiza no esforço de perseverar na existência e resistir aos desígnios do poder. Trata-se de um direito inalienável, que impede a transferência de direitos para o soberano, assim como teorizada por Hobbes. Transferir o conatus é impossível, pois ninguém pode transferir o desejo de existência de cada um. Como Guimarães (2004, p. 50) aponta "não há transferência plena de direitos, pois direito e exercício atual do mesmo são correspondentes".

O conatus torna-se o fundamento do conceito de imanência, assim que se supere o mecanismo de representação e delegação da vontade dos mesmos (Deleuze \& Guattari, 2002). Isso significa dar centralidade e um valor político à ação social que vem de baixo, valorizando o sujeito e reconhecendo que é na ação social que vive o corpo coletivo porque resiste e na resistência configura a realidade social (Negri, 2006). Assim, afirmando-se o plano de imanência, abre-se espaço para um espaço político que não é mais unicamente o gabinete de partido. É o sujeito que se torna central, o sujeito com sua vontade e sua participação, sem intermediação.

Já que, como Spinoza (1994) ressalta, não é possível substituir o direito natural pelo direito civil, o conflito torna-se constitutivo da política, tornando necessário encontrar formas e espaços de reafirmação do plano da imanência. A potência não trata apenas de uma qualidade individual, pois existe um desejo de expansão da mesma através do compartilhamento e da construção de um comum (Spinoza, 1994). Assim, os indivíduos se associam para expandir as próprias capacidades num movimento libertário de construção de espaços comuns de existência, exercendo um poder que não pode ser delegado. A interação torna-se um elemento constitutivo da imanência. Ao mesmo tempo, uma das condições necessárias para a criação de um espaço comum é a ausência de privilégios e a existência de relações iguais. Qualquer privilégio tende a criar distinções, diferenças e discriminações, impedindo a dinâmica relacional e de plena realização da potência individual e coletiva. Por isso, a horizontalidade é uma característica importante.

Outro elemento que desvitaliza a força transcendental é o exercício da autonomia. Segundo Guimarães (2004), o conceito de Virtú (virtude) de Machiavelli explica a autonomia, referindo-se à constituição de mecanismos de resistência, em contraposição à Fortuna (sorte). A Virtù depende de si mesma, do próprio valor, enquanto a Fortuna foge do controle de cada um, impossibilitando a ingerência em seus desígnios (Machiavelli, 2013). Assim, "Machiavelli expulsa da Virtù qualquer registro transcendente" (Guimarães, 2004, p. 44), na medida em que sua força está na autonomia do ser humano de agir e se expressar, superando determinações externas. Podemos concluir, assim, que tal perspectiva valoriza a autonomia na capacidade de resistir e alterar o real como elemento constitutivo de uma prática imanente.

Pensar na interação e horizontalidade leva a considerar outra variável central, que potencializa tais dinâmicas. Trata-se da transversalidade, que é, segundo Guattari (2004), uma dimensão que se realiza quando ocorre "uma comunicação máxima entre os diferentes níveis e, sobretudo, os diferentes sentidos" (p. 111). Isto permite superar as dicotomias de forma rizomática, na medida em que tudo se conecta, tornando-se fluido, permitindo superar todas as oposições binárias, incluindo as divisões hierárquicas e funcionais das instituições modernas.

O plano de imanência é, assim, reconstituído a partir da criação de espaços do comum, de relações iguais, do exercício da autonomia, assim como de superação de divisões dicotômicas e hierárquicas. Todo esse conjunto de elementos possibilita pensar formas participativas e de colaboração para a realização de projetos comuns, superando uma participação política que se manifeste apenas na expressão do voto, segundo os princípios de representatividade e soberania. Isto é assegurado também pela superação de divisões binárias e afiliações, na medida em que se funda na abertura para a participação e na lógica da inclusão transversal, permitindo que os sujeitos sejam autônomos e livres para participar e falar por si próprios, não sendo representáveis. Todos 
esses elementos permitem criar um novo sentido político e modos mais democráticos de se relacionar e agir, criando as bases para um novo modo de fazer política.

A RESAB age como um corpus imanente, capaz de desafiar toda a tradição da soberania? É importante lembrar que a mera organização e ação em rede não garante que seja democrática e imanente, por isso, torna-se necessária uma análise da forma como a RESAB opera, destacando as propriedades da interação, horizontalidade, autonomia e transversalidade, através das quais operacionaliza-se o conceito de imanência.

\section{INTERAÇÃO}

Compreender os processos de interação significa revelar as dinâmicas de compartilhamento, detectando se e de que forma se constrói o comum. Os membros da RESAB pertencem a instituições da mais variada natureza, incluindo instituições de ensino, secretarias governamentais e associações não governamentais, que atuam em 11 estados brasileiros. Apesar de tal diversidade, tais atores se unem em rede para expressar um determinado vínculo social entorno de uma causa comum[v]. Essa união é impulsionada pela conectividade, que é umas das propriedades morfológicas da rede, que ajuda a pensá-la como um campo de relações, a partir de um conjunto de conexões em torno de um objeto e objetivo compartilhados (Diani, 2003; Egler, 2007).

A comunicação é o processo estruturante da conectividade e da criação de um sistema denso de interações e relações, constituindo o "alimento da rede" (Martinho, 2003), seu tecido conectivo (Egler, 2007; ScherrerWarren, 2011). Tal processo pode ser analisado articulando a dimensão presencial e virtual na ação social da rede.

$\mathrm{Na}$ dinâmica de rede articulam-se diferentes momentos presenciais, entre os quais os encontros dos grupos gestores locais, a assembleia anual e os encontros da secretaria executiva. Trata-se de espaços deliberativos e executivos, mas também do terreno propício para a criação de vínculos e laços sociais (Martinho, 2003). Em cada estado existem grupos gestores locais, que implementam ações de educação contextualizada principalmente dentro das escolas, interferindo nas práticas pedagógicas escolares e, ao mesmo tempo, promovendo políticas públicas educacionais para o Semiárido nos espaços políticos municipais e estaduais, entre os quais fóruns e câmaras temáticas, conselhos, audiências públicas e conferências temáticas (por exemplo, a Conferência Nacional de Educação [CONAE]). Trata-se, assim, de uma ação localizada. A assembleia anual reúne representantes dos grupos gestores locais, constituindo o principal espaço decisório e de organização da gestão. É um espaço de avaliação e planejamento, assim como de definição das estratégias políticas, portanto, "não é um espaço onde todo mundo deve participar, pois não é um seminário ou um intercâmbio, mas um espaço de tomada de decisões" [viii]. Por isso, participam da assembleia as pessoas mais e ativas da rede, aquelas que podem ser chamadas de elos mais fortes.

A secretaria executiva representa o "braço executivo" da rede e se reúne com frequência bimestral ou trimestral.É composta por dois representantes dos estados que têm uma articulação e ação mais forte, isto é, os elos fortes da rede: Bahia, Piauí, Ceará, Alagoas e Paraíba. Tais representantes são eleitos durante a assembleia anual. A secretaria não tem caráter de comando ou deliberação política, mas um papel que a permite agilizar as operações da rede, sobretudo a execução dos encaminhamentos da assembleia anual. Além disso, tem a responsabilidade de organizar as reuniões e os encontros presenciais, representa a rede nos encontros em nível regional e nacional, assim como articula os grupos gestores locais nos estados com menor articulação, isto é, os elos fracos. Nesse sentido, representa a parte operacional da rede.

Coexistem, portanto, momentos presenciais de diferente natureza, nos quais participam apenas representantes da rede. Isto significa dizer que os momentos presenciais, as decisões tomadas na assembleia anual, a ação da secretaria executiva, assim como as experiências desenvolvidas localmente devem ser articuladas com a dimensão virtual, para que todos possam ser informados e participar de um processo de construção coletiva (Scherrer-Warren, 2011). Trata-se de uma dimensão fundamental para que se constituía como uma institucionalidade que opere de forma mais horizontal, apesar da dinâmica de 
representação. Isto evita que se consolidem elos sempre mais fortes e conectados, que, participando com mais regularidade, ganham importância e influência política, e elos cada vez mais fracos, com uma participação, um conhecimento e influência sempre menor.

$\mathrm{Na}$ RESAB a dimensão virtual limita-se ao uso do telefone, grupo de envio de e-mail e do aplicativo de mensagens instantâneas WhatsApp. O telefone e o grupo de e-mail são utilizados para comunicações operacionais, no que se refere à organização dos encontros presenciais, à participação em espaços políticos nacionais e à divulgação dos relatórios. É gerido pela secretaria executiva e tem um caráter operacional e informativo, de natureza individual e que não permite um nível elevado de interação. O grupo de WhatsApp, ao contrário, é bastante ativo, provendo comunicações diárias e processos de discussão e compartilhamento virtual. Apesar disso, conta com a presença de 40 pessoas e a participação ativa de apenas 15 pessoas, que constituem o núcleo duro da rede, isto é, os membros que participam reiteradamente das discussões, dos encontros nacionais e da secretaria executiva. Assim, o grupo de WhatsApp não inclui a totalidade dos membros, permanecendo um espaço comunicativo restrito.

A comunicação virtual da RESAB está, assim, concentrada nas mãos da secretaria executiva e dos elos fortes. Isto gera uma desconexão, na medida em que a informação e as discussões não acontecem livremente com a plena participação de todos os membros. Por isso, muitos membros de grupos gestores locais não mostram conhecimento dos acontecimentos que envolvem as ações da RESAB em nível regional. Quando a comunicação não flui, não há uma dinâmica plena de rede e diminuem as possibilidades de alcançar o pleno potencial em termos de organicidade e coesão (Hanneman, 2002). A conectividade é comprometida.

Existe outra dimensão relativa à conectividade na sua dimensão interna que caracteriza a RESAB como um sistema aberto que cresce pela incorporação de nós. O ponto de entrada na rede são os grupos gestores locais, ou porque um novo grupo é constituído ou porque novos membros se associam. A partir dos grupos gestores locais a rede pode crescer para um lado ou para outro, em ritmos e formas distintas e por razões diferentes, sendo, assim, totalmente imprevisível e com elevado dinamismo organizacional. A única condição é o interesse e compartilhamento de um projeto comum, ligado à ECCSA. Essas dinâmicas e características da rede definem um sistema em que "o fora da rede é todo o universo de pontos ainda não conectados" (Martinho, 2003, p. 22), numa dinâmica segundo a qual o que é central não são os pontos ou posições, mas as linhas de fuga (Deleuze \& Guattari, 1995). Essa abertura faz com que a RESAB sobreviva como organismo vivo (Capra, 1999), conferindo-lhe possibilidades organizacionais mais amplas dos modelos de organização tradicionais, que são mais rígidos, fechados e delimitados.

\section{HORIZONTALIDADE}

A conectividade como princípio organizativo da rede determina e é determinada por uma maneira potencialmente horizontal de operar, conferindo propriedades morfológicas de não linearidade e de extensão multidirecional e rizomática, segundo um processo pelo qual "a rede produz horizontalidade e a horizontalidade produz a rede" (Martinho, 2003, p. 17).

A ideia de horizontalidade significa diminuir a relevância de centros identificáveis, identificando uma forma descentralizada de operar e organizar, que potencialmente reduz a vulnerabilidade à ameaça de repressão e dominação (Castells, 2013). Esses tipos de propriedades influenciam o modo de operar e se organizar e vice-versa, determinando uma forma organizativa potencialmente sem hierarquias e autoorganizada.

A operacionalização da horizontalidade garante a ação colaborativa, pois garante as condições para a coprodução de todos e para uma dinâmica de reajuste recíproco, isto é, garante as condições para a produção em comum (Negri, 2012). Isto exige modos e formas de gestão diferentes das formas tradicionais de organização, possibilitando processos decisionais e operacionais inovadores, institucionalizando o comum 
como conteúdo de um governo colaborativo resultado de um processo de "des-hierarquização". Como isto se realiza na RESAB?

A forma como as decisões acontecem na rede permitem avaliar o nível de participação, de que forma é criado o consenso e, em geral, se está se constituindo uma gestão em comum. Para tanto, na medida em que as instâncias decisionais na RESAB são fundadas num princípio de representatividade, é fundamental compreender como acontece o processo de delegação, representação e compartilhamento. Isto é, a forma como representantes e representados participam.

$\mathrm{Na}$ assembleia nacional o princípio é garantir a participação de representantes de todos os estados, segundo um esquema de delegação de poder. Entre os membros da assembleia são eleitos também os membros da secretaria executiva, portanto, a dinâmica de representação e delegação na assembleia anual determina também a composição de tal órgão executivo.

Um elemento determinante da dinâmica de delegação é a rotatividade. Isto é, se e de que forma a rotatividade pode evitar a insurgência de hierarquias, determinando o nível de horizontalidade da rede. $\mathrm{Na}$ RESAB, por um lado, é garantida a rotatividade dos encontros, que acontecem em diferentes estados, seja a assembleia anual, seja a sede da secretaria executiva. Esse é um dos princípios, embora exista uma tendência a fazer assim que os estados com uma articulação mais forte predominem nessas duas esferas, como, por exemplo, a Bahia e a Paraíba. Por outro lado, não existe um sistema de delegação rotativo nos grupos gestores locais, isto é, não existem regras que garantam uma representação rotativa dos membros dos grupos na assembleia $^{[\mathrm{xiii}]}$. Assim, existem algumas pessoas que participam assiduamente e com maior frequência e que têm maior probabilidade se tornarem membros da secretaria executiva, na medida em que estes são eleitos durante a assembleia anual.

Esses membros podem ser considerados os elos fortes da rede (Egler, 2007; Scherer-Warren, 1999) ou hiperconectores (Barabási \& Bonadeau, 2003). Isto não necessariamente caracteriza uma tendência à centralidade, na medida em que nas redes sempre existem nos que são mais conectados, participam e se envolvem mais (Barabási \& Bonadeau, 2003). O problema surge quando esses elos fortes ou hiperconectores permanecem os mesmos, favorecendo o surgimento de uma hierarquia.

$\mathrm{Na}$ RESAB a falta de um sistema formal de rotatividade possibilita que os elos fortes participem dos encontros presenciais, tomem as decisões e implementem-nas operando na secretaria executiva, acumulando informações, conhecimento e experiências. Isto confere poder e cria um ciclo de empoderamento que permite acumular poder de saber, de decidir, de se relacionar com o poder público em nome da rede e de se tornar as pessoas de referência da rede, dominando de alguma forma o cenário de sua ação social.

A partir dessas considerações é possível reformular a representação da rede como na figura 2, destacando os elos fortes. A pesquisa possibilitou destacar os seguintes elos fortes: A Universidade Federal do Piauí, a Secretaria Estadual de Educação do Piauí, a Cáritas Diocesana de Crateús (CE), a Universidade Federal da Paraíba e a Universidade Federal de Campina Grande, a Rede de Educação Contextualizada do Agreste e Semiárido em Alagoas, a Universidade Estadual da Bahia, o Movimento de Organização Comunitária e o Instituto Regional da Pequena Agropecuária Apropriada. Dentro dessas organizações existem indivíduos de referência.

A criação e manutenção de elos fortes são acentuadas, senão determinadas, pelo fato de que o processo e a gestão comunicacional da rede não garantem um alto e extenso nível de participação dos membros da rede. A comunicação não possibilita uma temporalidade imediata e uma interação ampla e frequente, na medida em que a comunicação mais operacional é gerida pela secretaria de forma unidirecional e o WhatsApp envolve um número limitado de membros. Isto contribui para a concentração de poder nas instâncias intermediárias e seus representantes. 


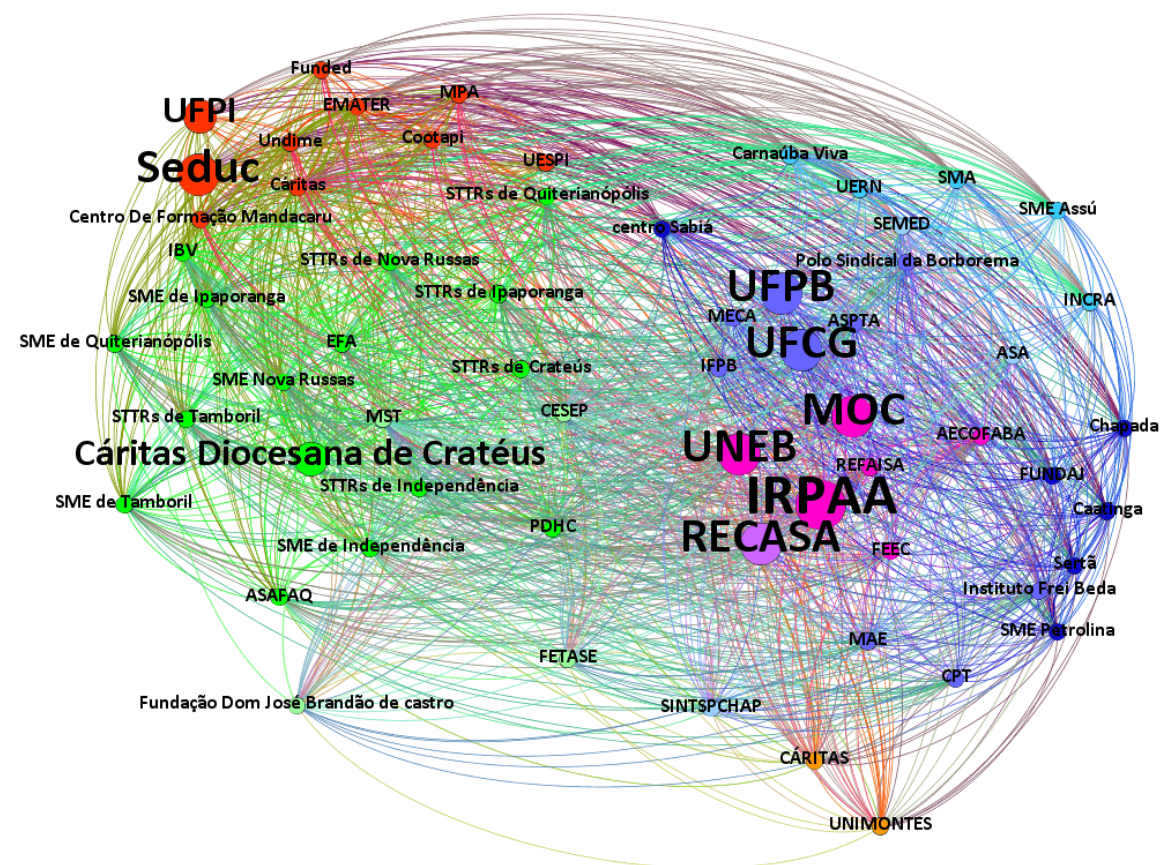

Figura 2 - Representação dos elos fortes

Fonte: Elaboração do autor, a partir da pesquisa e campo e do software GEPHI.

A comunicação é fundamental para pensar formas alternativas de poder e uma ação social que se constituía de forma horizontal e endógena. A comunicação não é só um meio, mas um insumo necessário para articular o presencial e o virtual, garantindo a dinâmica de uma organização sociopolítica de ampla participação e horizontal (Egler, 2007; Levy, 2003). Por isso, dever-se-ia tratar de uma comunicação plural e não linear, que não pode ser de mão única.

A análise da gestão do sistema comunicacional e as entrevistas confirmam que existe uma parte da rede que não participa diretamente do processo comunicacional, do compartilhamento e das decisões enquanto rede regional. Isto significa dizer que não participam do processo de construção coletiva e não se expõem às trocas, que criam o sentimento de pertencimento e o sentido da ação sociopolítica em rede. Existem, portanto, restrições ao funcionamento horizontal da comunicação, que se reflete e influencia o princípio de horizontalidade. Isto determina uma dinâmica organizativa e decisional descentralizada, mas não completamente distribuída, reduzindo o seu potencial produtivo, criativo e democrático.

\section{AUTONOMIA}

De todo modo, existe outra variável que ilumina a ação da RESAB e relativiza os obstáculos identificados para a realização da dinâmica do comum. Podemos imaginar de que forma a Virtù de Machiavelli se manifesta na ação social da RESAB, isto é, de que forma existe autonomia, entendida como a capacidade de um sujeito ou um grupo de definir as próprias regras, modos de operar e princípios (Castoriadis, 1988). 
A autonomia refere-se a duas dimensões. A primeira, em relação à prática difusa, ou seja, a prática segundo a qual cada integrante ou grupo toma as próprias decisões e apreende ações, independentemente da consulta ao grupo (Martinho, 2003). Os membros ou grupos gestores locais da RESAB têm plena autonomia para pensar e implementar práticas educacionais dentro e fora das escolas, assim como de desenvolver ações de diálogo e negociação com o poder público.

A RESAB opera, assim, como uma somatória de ações simultâneas diferenciadas dos diferentes grupos locais, caracterizando uma estrutura organizacional policéfala (Martinho, 2003). Isto permite que se dilua o poder, mas, ao mesmo tempo, que se fortaleça a ação de cada grupo quando o poder da rede converge para o grupo que age em nome dela. Nesses momentos, o grupo "deixa de ser um pedaço do conjunto para tornarse um meio pelo qual o conjunto se exerce. A rede está inteira em cada ponto" (pag. 47).

A segunda importante dimensão da autonomia prevê que as conexões aconteçam de forma não previsível e linear. Nas organizações de tipo vertical a autonomia é um requisito de entrada, mas com dificuldade e muitos limites pode ser exercida depois, definindo uma perda de poder pelos indivíduos. Ao contrário, na RESAB existem relações e dinâmicas emergentes que são criadas pela e na prática cotidiana. As relações, as trocas e as atividades entre os membros geram novas ideias, parcerias e ações políticas, seguindo uma dinâmica de autonomização da ação difusa em rede. Nesse sentido, a autonomia dos grupos gestores locais determina uma desconcentração do poder e confere dinamicidade à ação da RESAB. Isto, de alguma forma, contrabalança as dificuldades na realização de uma "ação concertada" enquanto rede em nível regional e nacional, que são causadas pela participação e horizontalidade limitada.

\section{TRANSVERSALIDADE}

A dinâmica de conexão e horizontalidade cria as condições para a superação de limites institucionais, setoriais e delimitações geográficas. Em poucas palavras, cria condições de transversalidade que na RESAB pode ser abordada a partir da integração das diversidades, articulando o individual e o coletivo, o pluralismo e a identidade, o local e o global (Scherer-Warren, 1999).

A RESAB configura-se como uma teia de relações entre instituições de diferentes naturezas e indivíduos ${ }^{\text {[xvii] }}$. Trata-se de indivíduos que, devido a fatores pessoais, culturais ou profissionais, têm interesse em participar da rede, independentemente da própria afiliação institucional. Isto significa dizer que, ao contrário das instituições clássicas, os sujeitos criam o próprio projeto e a própria institucionalidade política, associando-se de forma voluntária e, portanto, segundo princípios que escapam de uma lógica meramente econômica (Melucci, 2001). Isto cria um forte laço ético, que supera a nítida separação entre a esfera individual e a coletiva.

Além de associar indivíduos e instituições, a RESAB garante o pluralismo, uma vez que seus membros fazem parte de muitas organizações distintas, que atuam em setores e atividades diversas, garantindo riqueza no debate e na construção coletiva. O pluralismo é representado também pela composição mista, isto é, a participação de membros da esfera governamental e não governamental. Essa característica da rede comprova como é cada dia mais difícil fixar fronteiras rígidas entre essas duas esferas, na medida em que a constituição de redes oferece um espaço híbrido de partilha de poder e de atuação (Castells, 2013). O conceito de hibridização faz repensar, também, o papel do "adversário", na medida em que o poder público é membro da RESAB, segundo uma lógica de inclusão. O princípio norteador da rede é "trabalhar em conjunto para difundir um novo jeito de fazer, de cooperar e aprender", promovendo uma nova forma de produzir e colaborar também com os responsáveis para a elaboração e a implementação das políticas públicas (Martinho, 2003).

Se, por um lado, a ação em rede garante um equilíbrio entre singularidade e pluralismo, individual e coletivo, permitindo abordar e satisfazer a noção de diversidade, por outro lado, expressa também uma identidade fortemente constituída. Na RESAB o pluralismo se entrelaça numa mesma totalidade com a noção de identidade. A identidade é constituída pelo sentido da sua existência e da sua ação social, na medida 
em que é uma comunidade de propósitos com um objetivo comum (Castells, 2000). Na RESAB a proposta de ECCSA é o elemento que garante a coesão da pluralidade. O objetivo comum é, portanto, o que faz o papel de coordenação e estímulo tradicionalmente desempenhado pelo comando e controle centralizado e pela coerção hierárquica (Lipnack \& Stamps, 2004).

Além da articulação entre o individual e o coletivo, entre identidade e pluralismo, a transescalaridade materializa-se também na estrita relação entre o global e o local. Nesse sentido, podemos definir a ação da RESAB como transescalar, na medida em que articula diferentes níveis estratégicos e territoriais no exercício de sua ação sociopolítica. Os membros da RESAB exercem uma ação cotidiana em nível local nos municípios, articulam-se politicamente em nível de fóruns e redes e se mobilizam através de marchas e campanhas nacionais.

A articulação de tais níveis reorganiza espacialmente a ação social da RESAB através de um processo de desterritorialização e reterritorialização (Musso, 2013). Cria-se um novo espaço ampliado que articula a organização de base com outros níveis de articulação política. Isto permite garantir um diálogo entre as experiências concretas de base com instâncias políticas em nível local, estadual, regional e nacional, articulando ações desenvolvidas na vida cotidiana com as discussões de políticas públicas.

As ações que acontecem nas escolas, as negociações e políticas públicas aprovadas nos municípios e os programas estaduais onde foi inserida a educação contextualizada, por exemplo, são apresentados e compartilhados nos momentos presenciais entre os membros. Isto permite divulgar e discutir as questões locais, pensando e desenvolvendo uma estratégia de ação enquanto rede. Isto possibilita um movimento de "baixo para cima", que permite deslocar e levar as demandas e as questões locais para um nível político estadual, regional e nacional, na medida em que entram na pauta da rede.

A transversalidade, com sua intrínseca superação de binômios, possibilita um movimento de desconstrução das tradicionais dicotomias e a articulação de dimensões que são tradicionalmente distintas e separadas. Assim, na composição da RESAB articulam-se e unem-se o individual e o coletivo, o pluralismo e a identidade, o local e o global, caracterizando uma nova institucionalidade política.

\section{CONCLUSÃo}

Pensar o potencial democrático da RESAB a partir de sua ação imanente e da capacidade de reorganizar as relações de poder significa considerar a capacidade de manifestar resistência ao "velho" poder e de construir um novo que liberte (Gohn, 2011). Isto compõe o seu poder constituinte, ou seja, a capacidade de expressar a potência subjetiva voltada para a mudança, através da ação em comum e para o comum (Negri, 2002).

Embora existam entraves para uma ação plenamente participativa e horizontal, pois a dinâmica de delegação e comunicacional limita a participação plena e igualitária de todos, a RESAB se diferencia das instituições políticas tradicionais, na medida em que é uma institucionalidade mais aberta, articuladora das diversidades e por natureza transversal. Todos podem participar, colaborar e desenvolver propostas num processo de construção coletiva e comum, exercendo sua autonomia, em particular em nível local, como mostrado ao longo do artigo.

Em relação à construção de um novo poder que liberte, a RESAB proporciona um conjunto de inovações culturais, sociais e políticas, "de baixo para cima", a partir da diversidade de experiências e da construção de um projeto comum por parte de seus membros, que se realizam na ação da rede enquanto institucionalidade política. Isto constitui seu poder constituinte e democrático. Representa, por exemplo, o poder que todos os membros da RESAB têm de transformar a realidade educacional e contribuir para um novo projeto político.

Do ponto de vista educacional, a RESAB é responsável por uma importante inovação teórica e epistemológica, na medida em que elabora, a partir da junção das experiências pedagógicas no Semiárido, uma teoria de educação contextualizada. Trata-se de uma teoria construída, fazendo emergir, juntando e compartilhando discursos e experiências educacionais contra hegemônicas. É uma inovação por essência 
imanente, que emerge. Além disso, é ativamente envolvida na difusão de tais inovações epistemológicas. Por isso, criou 12 cursos de especialização em educação contextualizada na Bahia, no Piauí, na Paraíba e no Ceará, assim como desenvolveu o próprio selo editorial para publicar livros sobre educação no Semiárido.

Partindo da enunciação discursiva da RESAB, com suas conotações simbólicas, constitui-se um campo sociopolítico, que compõe o terreno onde se definem o sentido e as ações concretas da ação social, assim como a estratégia de resistência em relação ao poder constituído, ao "velho que oprime" (Gohn, 2011). Nesse sentido, a rede atua no sentido de influenciar e transformar as instituições políticas tradicionais e suas políticas públicas (Bringel \& Echart, 2008; Scherrer-Warren, 2011). Tais instituições mesclam hierarquias e verticalidades, provocando sistemas burocráticos e patrimonialistas. Segundo Moura (1997), as redes como arranjos organizacionais indicam o esgotamento da capacidade de gestão das instituições representativas, da capacidade de planejar das instituições burocráticas e centralizadas.

Assim, a RESAB amplia os espaços de participação, articulando diferentes níveis políticos e constituindo uma institucionalidade política regional. "A criação da rede nos dá maior força política, nos torna mais importante e influentes politicamente" ${ }^{[\mathrm{viii}]}$. Ao mesmo tempo, consegue fortalecer a própria influência e incidência, na medida em que define um novo contexto relacional no qual atores governamentais e não governamentais entram em sinergia. A diversidade, sobretudo relativa à característica sociogovernamental, realiza intencionalmente um princípio político, assim como possibilita uma inovação organizativa e política.

Isto configura uma nova relação política e a possibilidade de ter um maior peso político nas políticas públicas, promovendo sinergias e convergências entre as duas esferas. No município de Crateús, por exemplo, a participação do Instituo Federal do Ceará no grupo local da RESAB criou a possibilidade de fundar um curso em educação contextualizada. Da mesma forma, no Piauí, a coordenadora do Projeto Mais Viver da Secretaria Estadual de Educação (SEDUC) é membro da RESAB e defende a realização de ações de educação contextualizada na secretaria. Isto não somente amplia os espaços de participação, mas também amplia o espaço de afirmação e implementação da ECCSA. Além disso, com o intuito de garantir o reconhecimento político da rede, a RESAB tem, segundo tradicionais formas de participação, representantes em comissões e conselhos, tais como a Comissão Nacional de Educação do Campo (Conec) do Ministério da Educação, no Fórum Nacional de Educação do Campo (Fonec), no Conselho Nacional do Desenvolvimento Rural Sustentável (Condraf) vinculado ao Ministério do Desenvolvimento Agrário (MDA), no Instituto Nacional do Semiárido (Insa) do Ministério da Ciência, Tecnologia e Inovação (MCTI), no Conselho Nacional de Segurança Alimentar (Consea).

Em termos de formulação ou controle social das políticas públicas, os resultados da ação sociopolítica da RESAB podem ser observados de forma transescalar em nível nacional, estadual e local. Em nível municipal são observáveis resultados concretos em termos de aprovação de projetos de lei, como a lei municipal de educação contextualizada nos municípios de Tamboril e Ipaporanga no estado do Ceará, e no município de Curaça na Bahia. Em três municípios do Ceará foi implementada a educação contextualizada em todas as escolas municipais e em outros municípios adotaram nas escolas o livro didático produzido pela RESAB, "Conhecendo o Semiárido", volumes I e II. Em geral, a pesquisa revelou que a RESAB conseguiu resultados mais importantes em nível municipal.

Alguns dos resultados em nível municipal dependem da ação rizomática da RESAB, na medida em que molda subjetividades. Essas subjetividades quando, por exemplo, dizem respeito a gestores públicos, têm uma maior sensibilidade e interesse em incluir a ECCSA na pauta governamental. O envolvimento e o conhecimento da proposta pedagógica alternativa sensibiliza os gestores municipais, aumentando a probabilidade de se comprometerem com a implementação da ECCSA nas escolas, assim como com a elaboração de políticas públicas educacionais contextualizadas. Por isso, não surpreende que uma boa parte dos gestores públicos envolvidos na educação contextualizada tenham uma formação ligada à educação popular ou à educação contextualizada. 
Isto demonstra que a ação social da RESAB é constituída, também, por dinâmicas que se desenvolvem no cotidiano e envolvem o lado subjetivo, não se esgotando em si mesma. Por isso, é possível identificar todo um conjunto de efeitos multiplicadores, que não são planejáveis e previsíveis, encontrando-se na dimensão do incalculável. Novos grupos da rede são criados, novas relações com a esfera governamental e novas aberturas para a ação social da rede. Isto é resultado da dinâmica das conexões, do caráter formativo da ação social e do envolvimento de dinâmicas com fortes conotações subjetivas.

A dinâmica da conexão, a autonomia e flexibilidade de cada grupo, a sinergia entre esfera governamental e não governamental e a colaboração são os elementos que caracterizam uma ação social nova e inovadora. É aqui que se encontram as sementes da futura democracia. Uma democracia por vir, na medida em que a rede é um constante processo de aprendizagem ética, centrado no compartilhamento e na ação em comum, que constituem valores fundamentais para a construção de um novo campo ético-político (Gohn, 2011). Estamos nos referindo a uma concepção de democracia que não é o governo de um, mas a "democracia do múltiplo", do conjunto de processos múltiplos que constituem o comum (Negri, 2012a). Este constitui o tipo de democracia, que pode se realizar e efetivar no plano da imanência.

\section{REFERÊNCIAS}

Barabási, A. L., Bonadeau, E. (2003). Redes sem escala. Revista Scientific American Brasil, 12(13), 64-72.

Bringel, B., Echart. (2008). Movimentos sociais e democracia: os dois lados das "fronteiras". Cad. CRH, 21 (54), 457-475.

Capra, F. (1999). O ponto de mutação: a ciência, a sociedade e a cultura emergente. 21. ed. São Paulo: Cultrix.

Carvalho, L. D. (2007). As representações políticas e geográficas sobre o Semi-Árido Brasileiro e o planejamento e gestão territorial. In RESAB (Org.), Currículo, contextualização e complexidade: elementos para pensar a escola no Semi-Árido. Juazeiro/BA: selo editorial RESAB.

Castells, M. (2000). O Poder da Identidade. São Paulo: Paz e Terra.

Castells, M. (2013). Redes de indignação e esperança. Movimentos sociais na era da internet. Tradução: Carlos Alberto Medeiros. Rio de Janeiro: Zahar.

Castoriadis, C. (1988). Pouvoir, politique, autonomie. Revue de Métaphysique et de Morale, 93(1), 81-104.

Dalton, R. (2004). Democratic Challenges, Democratic Choices: The Erosion of Political Support in Advanced Industrial Democracies. New York: Oxford University Press.

Deleuze, G., Guattari, F. (2002). O que é a filosofia?São Paulo: Editora. 34.

Della Porta, A., Diani, M. (2006). Social movements: an introduction. Oxford: Blackwell publishing.

Diani, M. (2003). Networks and Social Movements: A Research Programme. In Diani, M. McAdam, D. (Org.) Social Movements and Networks - Relational Approaches to Collective Action. Oxford: Oxford Univ. Press.

Diap - Departamento Intersindical de Assessoria Parlamentar. (2011). Bancada ruralista aumenta com o reforço de novos parlamentares". Reporter Brasil. Recuperado de http://reporterbrasil.org.br/2011/01/bancada-ruralistaaumenta-com-o-reforco-de-novosparlamentares/

Egler, T. T. C. (2007). Ciberpólis: redes no governo da cidade. Rio de Janeiro: 7letras.

Gomes, G. M. (2001). Velhas secas em novos sertôes: continuidade e mudanças na economia do semi-árido e dos cerrados nordestinos. Brasília: Ipea.

Gohn, M. da G. (2011). Movimentos sociais na contemporaneidade. Revista Brasileira de Educação, 16 (47), 333-361.

Guattari, F. (2004). Psicanálise e transversalidade: ensaios de análise institucional. Aparecida/SP: Idéias \& Letras.

Guéhenno, J. M. (1999). O Fim da Democracia: um ensaio profundo e visionário sobre o próximo milênio. 2. ed. Rio de Janeiro: Bertrand Brasil.

Guimarães, F. de. (2004). Poder constituinte em Espinosa e Maquiavel: a perspectiva da imanência. Lugar Comum Estudos de Midia, Cultura e Democracia, 19(20), 41-61. 
Hanneman, R. A. (2002). Propiedades básicas de las redes y de los actores. In Hanneman, R. A. Introducción a los métodos del análisis de redes sociales. Departamento de Sociología de La Universidad de California Riverside (capítulo 5).

Hardt, M., Negri, A. (2000). O império. Rio de Janeiro: Record.

Hardt, M., Negri, A. (2005). Multidão: guerra e democracia na era do Império. Rio de Janeiro: Record.

Hobbes, T. (1985). Leviathan. London: Penguin.

Lévy, P. (2003). A inteligência coletiva: por uma antropologia do ciberespaço. 4. ed. São Paulo: Loyola.

Lipnack, J., Stamps, J. (1994). Rede de informaçôes. São Paulo: Makron Books.

Machiavelli, N. (2013). Il principe. Milano: Feltrinelli.

Martinho, C. (2003). Redes - Uma Introdução Às Dinâmicas da Conectividade e da Auto-Organização. Brasília: WWF Brasil.

Martins, J. da S. (2005). Tecendo a rede. Notícias criticas do trabalho de descolonização curricular no semi-árido brasileiro e outras excedências. (Tese de Doutorado). Universidade Federal da Bahia, Salvador, Brasil.

Melucci, A. (2001). A invenção do presente - Movimentos sociais nas sociedades complexas. Petrópolis: Vozes.

Ministério Do Meio Ambiente. (2008). Atlas das áreas susceptiveis à desertificação do Brasil. Brasília: Ministério do Meio Ambiente.

Moulaert, F., Martinelli, F., Swyngedouw, E., Gonzalez, S. (2005). Towards Alternative Model(s) of Local Innovation. Urban Studies, 42(11), 1669-1990.

Moura, S. (1997). A construção de redes públicas na gestão local: algumas tendências recentes. Revista de Administração Contemporânea, 1(1), 67-85.

Musso, P. (2013). A filosofia da rede. In Parente, A. (org.), Tramas da rede: novas dimensóes filosóficas, estéticas epoliticas da comunicação (pp. 17 -38.. Porto Alegre: Sulina.

Negri, A. (1981). L'anomalia selvaggia. Saggio su potere epotenza in Baruch Spinoza. Milano: Feltrinelli.

Negri, A. (2002). Opoder constituinte: ensaio sobre as alternativas da modernidade. Rio de Janeiro: DP\&A.

Negri, A. (2006). Fabrique de porcelaine. Pour une nouvelle grammaire du politique. Paris: Stock.

Negri, A. (2012). Il comune in rivolta. Sul potere costituente delle lotte. Verona: Ombre Corte.

Passy, F. (2003). Social Networks Matter. But How?. In Diani, M., Mcadam, D. (org.), Social Movements and Networks (21 - 48). Oxford/New York: Oxford University Press.

Pharr, S.; Putnam, R. (2000). Disaffected Democracies: What's Troubling the Trilateral Countries? Princeton: Princeton University Press.

Rede de Educação do Semiárido Brasileiro - RESAB. (2006). Educação para a convivência com o Semi-Árido: reflexões teórico-práticas. 2a Edição, Juazeiro/BA: Secretaria executiva da rede de educação do Semi-Árido brasileiro, Selo editorial RESAB.

Rousseau, J. (1973). O Contrato social. São Paulo: Abril cultural.

Santos, B. de S. (2002). Para uma sociologia das ausências e uma sociologia das emergências". Revista Crítica de Ciências Sociais, 63(1), 237-280.

Santos, B. de S., Avritzer, L. (2002). Para ampliar o cânone democrático. In Santos, B de S. (org.), Democratizar a democracia: os caminhos da democracia participativa. Rio de Janeiro: Civilização Brasileira.

Scherer-Warren, I. (1999). Metodologia de redes no estudo de ações coletivas e movimentos sociais. In SchererWarren, I. (org), Cidadania sem fronteiras: açôes coletivas na era da globalização (pp. 21-30). São Paulo: Hucitec.

Scherer-Warren, I. (2011). Redes da sociedade civil: advocacy e incidências possíveis. In Martinho, C., Felix, C. (org.), Vida em rede: conexóes, relacionamentos e caminhospara uma nova sociedade (65 - 86). Barueri, SP: Instituto C\&A.

Singer, P. (1965). A política das classes dominantes. In Ianni, O. (org.). Política e revolução social no Brasil. Rio de Janeiro: Civilização Brasileira.

Spinoza, B. (1994). Tratado político. Tradução de Norberto de Paula Lima. São Paulo: Ícone. 


\section{Notas}

[i]Participação observante 3 - Assembleia anual RESAB, Maceió/AL, 23-24 de abril de 2014.

[ii]Entrevista 10 - membro RESAB, 10 de outubro de 2014.

[iii]Entrevista 6 - membro RESAB, 7 de outubro de 2014.

[iv]Figura 1: PIAUÍ - Secretaria Estadual de Educação (SEDUC), Universidade Federal do Piauí (UFPI), Universidade Estadual do Piauí (UESPI), Empresa de Assistência Técnica e Extensão Rural (Emater), Cáritas, Cooperativa de Producão e Servicos de Tecnicos Agricolas do Piaui \&Associados (Cootapi), Fundação Dom Edilberto Dinkelborg (Funded), Centro De Formação Mandacaru, MPA, União dos Dirigentes Municipais de Educação (Undime); CEARÁ - Cáritas Diocesana de Crateús (CDC), Projeto Dom Helder Camará (PDHC), Escola Família Agrícola Dom Fragoso (EFA), Instituto Federal do Ceará (IFCE), Secretaria Municipal de Educação (SME) de Ipaporanga; SME de Tamboril; SME Nova Russas; SME de Independência; SME de Quiterianópólis; Sindicato Dos Trabalhadores Rurais (STTRs) de Ipaporanga; STTRs de Tamboril; STTRs Nova Russas; STTRs de Independência; STTRs de Quiterianópólis; Sindicato dos professores de Crateús; Movimento Sem Terra (MST); Instituto Bem Viver (IBV); Associacão dos agricultores familiares de quintais produtivos de Quiterianópolis (ASAFAQ); BAHIA - Universidade Estadual da Bahia (UNEB), Associação Escolas Comunidades Famílias Agrícola (AECOFABA), Instituto Regional da Pequena Agropecuária Apropriada (IRPAA), Movimento de Organização Comunitária (MOC), Fórum estadual de Educação do Campo (FEEC), Rede de Escolas Família Agrícola Integradas do Semiárido (REFAISA); ALAGOAS - Rede de Educação Contextualizada do Agreste e Semiárido (RECASA); PARAÍBA - Comissão Pastoral da Terra (CPT), Polo Sindical da Borborema, Assessoria e Serviços a Projetos em Agricultura Alternativa (ASPTA), Instituto Frei Beda, MECA, MAE, Universidade Federal de Campina Grande (UFCG), Universidade Federal da Paraíba (UFPB), Instituto federal da Paraíba (IFPB); MARANHÃO - Articulação do Semiárido (ASA), Sindicato dos Trabalhadores no Serviço Público do Estado do Maranhão (SINTSPCHAP), Secretaria Municipal de Educação de São Luís (SEMED); SERGIPE - CÁRITAS, Federação dos Trabalhadores na Agricultura do Estado de Sergipe (FETASE), MST, Fundação Dom José Brandão de Castro, Centro Sergipano de Educaçăo Popular (CESEP); MINAS GERAIS - Universidade Estadual de Montes Claros (Unimontes), Cáritas; PERNAMBUCO - Centro Sabiá, Chapada e Caatinga, Sertã, Secretaria Municipal de Educação de Petrolina, Fundação Joaquim Nabuco (FUNDAJ); RIO GRANDE DO NORTE - Carnaúba Viva; Secretaria de Meio Ambiente; EMATER; Incra, UERNAssu, Secretaria de Educação - Assú.

[v]Participação observante 3 - Assembleia anual RESAB, Maceió/AL, 23-24 de abril de 2014.

[vi]Entrevista 1 com membro grupo gestor local do Ceará - 15 de março de 2014; entrevista 9 com membro da secretaria executiva, 9 de outubro de 2014 .

[vii]Entrevista 5 com membro do grupo local do Ceará, 22 de março de 2014; entrevista 2 com assessor pedagógico da RESAB, 17 de março de 2014; participação observante 8 - reunião grupo gestor local da RESAB de Crateús/CE, maio de 2016. [viii] Entrevista 9 com membro da secretaria executiva, 9 de outubro de 2014.

[viii]Entrevista 9 com membro da secretaria executiva, 9 de outubro de 2014.

[ix]Entrevista 1 com membro grupo gestor local do Ceará - 15 de março de 2014.

[x]Entrevista 1 com membro grupo gestor local do Ceará - 15 de março de 2014; entrevista 16 com membro grupo gestor local do Ceará - 16 de novembro de 2015; grupo focal 5 com assessores pedagógicos do grupo gestor local do Ceará.

[xi]Participação observante 3 - Assembleia anual RESAB, Maceió/AL, 23-24 de abril de 2014.

[xii] Entrevista 6 - membro RESAB e da secretaria executiva, 7 de outubro de 2014. [xiii] Entrevista 4 - membro grupo gestor local do Ceará, 20 de março de 2014.

[xiii]Entrevista 4 - membro grupo gestor local do Ceará, 20 de março de 2014.

[xiv]Participação observante 3 - Assembleia anual RESAB, Maceió/AL, 23-24 de abril de 2014; participação observante 4 reunião secretaria executiva da RESAB 7 de outubro de 2014.

[xv]Entrevista 3 - membro grupo gestor local do Ceará, 18 de março de 2014; entrevista 29 - membro secretaria executiva, 12 de setembro de 2016. 
[xvi]Participação observante 1 - intercâmbio interestadual da RESAB (Piauí, Bahia e Ceará), 12 e 13 de março de 2014; Entrevista 7 - professora escola municipal da Bahia, 8 de outubro de 2014.

[xvii]Participação observante 5 - intercâmbio nacional de educação contextualizada, 25-27 de março de 2015; Participação observante 3 - Assembleia anual RESAB, Maceió/AL, 23-24 de abril de 2014.

\section{BY-NC-ND}

